\title{
Respeitável público: espetacularização e popularização do futebol profissional no Rio de Janeiro (1933-1941)
}

\author{
Respectable audience: spectacularization and popularization of \\ football in Rio de Janeiro (1933-1941)
}

\author{
Eduardo de Souza Gomes \\ Universidade Federal do Rio de Janeiro (UFRJ), Rio de Janeiro / Brasil \\ Doutorando em História Comparada, UFRJ \\ eduardogomes.historia@gmail.com
}

\begin{abstract}
RESUMO: Este artigo possui como objetivo analisar as relações existentes entre o processo de profissionalização do futebol no Rio de Janeiro (1933-1941) e a construção de uma lógica espetacularizada desse esporte na cidade, tal como no Brasil. A partir da análise de fontes periódicas e obras do período, buscamos entender como a espetacularização e a popularização do futebol, sendo ambos processos iniciados nos primórdios do século XX, se efetivaram definitivamente com o avanço da profissionalização dessa prática, iniciada no Rio de Janeiro durante a década de 1920 e consolidada nos anos 1930. Entendemos que esse cenário propiciou a ampliação do público e do mercado em torno do futebol, assim como a construção de discursos e o uso desse esporte enquanto fim político nacionalista, notadamente no contexto do Estado Novo varguista (1937-1945).
\end{abstract}

Palavras-Chave: Futebol; Rio de Janeiro; Profissionalização; Espetacularização; Popularização.

ABSTRACT: This article has as objective to analyze the relations existing between the process of professionalization of football in Rio de Janeiro (1933-1941) and the construction of a logic spectacular this sport in the city, as in Brazil. From the analysis of regular sources and works of the period, we seek to understand how spectacularization and the popularization of football, and both processes started in the beginning of the 20th century, were definitely made effective with the advancement of the professionalism of this practice, which began in Rio de Janeiro during the 1920s and consolidated in the 1930s. We believe that this scenario resulted in the expansion of the public and the market around the football, as well as the construction of discourses and the use of the sport while political end nationalist, notably in the context of the New State varguista (1937-1945).

Keywords: Football; Rio de Janeiro; Professionalism; Spectacularization; Popularization. 


\section{INTRODUÇÃO}

Este artigo possui como objetivo analisar as relações existentes entre o processo de profissionalização do futebol no Rio de Janeiro e a construção de uma lógica espetacularizada desse esporte na cidade, sem, entretanto, deixarmos de abordar as relações com o contexto nacional então vigente. Buscamos identificar, a partir da análise de fontes periódicas e obras da época, como se forjaram discursos pelo futebol que disseminaram a ideia de que essa prática seria uma das formas possíveis para se pensar a identidade nacional brasileira, sendo esse um dos aspectos consolidadores da popularização desse esporte no país, estabelecendo um processo que já havia se iniciado desde os primórdios do século XX.

Nesse exercício, analisamos alguns jornais do Rio de Janeiro que nos permitiram melhor compreender como se deu o processo de profissionalização do futebol na cidade, tal como seus efeitos no Brasil. Problematizamos também obras e artigos escritos por autores do período que tiveram influência direta na construção do futebol enquanto um símbolo de identidade nacional no país, como Gilberto Freyre ${ }^{1}$ e Mário Rodrigues Filho. ${ }^{2}$

$\mathrm{Na}$ constituição de um campo esportivo profissional do futebol no Rio de Janeiro, ocorreram diversas iniciativas para que essa prática fosse entendida na lógica de um espetáculo. Desde já, destacamos que trabalhamos com o conceito de espetáculo definido por Clark, onde o define como:

[...] uma tentativa - parcial e inacabada - de trazer ao campo teórico uma série variada de sintomas em geral tratados pela sociologia burguesa ou pela esquerda convencional como etiquetas anedóticas aplicadas de forma um tanto leviana à velha ordem econômica: "consumismo", por exemplo, ou "sociedade do lazer"; a emergência dos meios de comunicação de massa, a expansão da publicidade, a hipertrofia das diversões oficiais. ${ }^{3}$

A partir desse olhar, podemos inferir que a inclusão do futebol na lógica das sociedades espetacularizadas na década de 1930, fez com que esse esporte profissional pudesse alcançar diferentes públicos, de forma que não se restringisse apenas aos grupos dominantes da modalidade até então. Não afirmamos, com isso,

\footnotetext{
${ }^{1}$ Ver FREYRE. Foot-ball mulato.

${ }^{2}$ Ver RODRIGUES FILHO. O negro no futebol brasileiro.

${ }^{3}$ CLARK. A pintura da vida moderna, p. 43.
} 
que o futebol era praticado apenas por parte da elite até os anos 1920, sendo essa uma hipótese frágil e já bastante problematizada. ${ }^{4}$ Todavia, destacamos que é na década de 1930 que a consolidação dessa popularização do futebol, a partir de uma lógica comercial e espetacularizada, se dá de maneira mais plena, muito devido ao processo de profissionalização pelo qual passava a prática. Com isso, podemos concluir que esse processo não se tratava de uma novidade, mas sim, de uma consolidação da lógica espetacularizada que se desenhava pelo futebol desde os primórdios do século XX. Como escreve Pierre Bourdieu, o futebol após sua difusão em uma determinada localidade, se encaixava entre os esportes populares, ou seja, de massa,

[...] que funcionam como espetáculos (que podem dever uma parte de seu interesse à participação imaginária que a experiência passada de uma prática real autoriza): eles são 'populares', mas no sentido que reveste este adjetivo todas as vezes em que é aplicado aos produtos materiais ou culturais da produção de massa [...]. Em suma, o esporte, que nasceu dos realmente populares, isto é, produzidos pelo povo, retorna ao povo, como a folk music, sob a forma de espetáculos produzidos para o povo. ${ }^{5}$

Com isso, explicitaremos na sequência do artigo como se deu o processo de profissionalização do futebol no Rio de Janeiro, demonstrando suas relações com o avanço da construção de espetáculos nessa modalidade esportiva, algo que já ocorria anteriormente, mas que se fortaleceu como nunca com a passagem do amadorismo para o profissionalismo.

\section{UMA BREVE ANÁLISE DA PROFISSIONALIZAÇÃO DO FUTEBOL CARIOCA}

No objeto aqui estudado, ocorreram diferentes adaptações e absorções da noção de espetáculo relacionada ao futebol. Notadamente, a difusão do espetáculo por esse esporte no Rio de Janeiro se fortaleceu nos anos 1930, a partir da idealização dessa prática como um possível símbolo da nacionalidade brasileira. Isso permitiu a difusão dessa ideia por diversas vias, como o rádio e a grande imprensa impressa, fazendo com que fosse idealizado um esporte que pudesse em

\footnotetext{
${ }^{4}$ Alguns trabalhos, como SANTOS JÚNIOR. A construção do sentimento local; PEREIRA. Footballmania; e MASCARENHAS. Entradas e bandeiras, reforçam a hipótese de que a prática do futebol por classes populares já ocorria desde os primórdios desse esporte no Brasil.

${ }^{5}$ BOURDIEU. Como se pode ser desportista?, p. 191.
} 
seus palcos, que eram os estádios, abarcar diferentes públicos de forma mais ampla.

Outro importante fator para a difusão dessa imagem que relacionava o futebol com a identidade nacional, fundamental no desenvolvimento de espetáculos desse esporte no Rio de Janeiro, foi a atuação de intelectuais do período, como os já citados Gilberto Freyre e Mário Rodrigues Filho. Ambos contribuíram para a difusão da ideia de que esse esporte se caracterizaria como símbolo de identidade na capital e no Brasil como um todo. Somando-se ao olhar para a prática que foi destinado pelos veículos da grande imprensa do período, se consolidaram assim os fatores necessários para a efetivação da lógica espetacularizada no futebol. Como nos escreve Renato Soares Coutinho:

[...] vale ressaltar que esses valores difundidos pelos jornais também estavam presentes nas transmissões de rádio, fundamentais para a nacionalização do clube. As redes de sociabilidade da época permitiam a articulação dos radialistas com os redatores de jornais. Ary Barroso, símbolo maior do rádio esportivo brasileiro, buscava suas referências nas mesmas fontes que Mário Filho e exaltava o mesmo significado de nação que o Jornal dos Sports. ${ }^{6}$

A partir de 1933, efetivaram-se no Rio de Janeiro dois campeonatos de futebol que rivalizavam na cidade, um profissional, organizado pela Liga Carioca de Football (LCF) e outro amador, organizado pela Associação Metropolitana de Esportes Athleticos (AMEA). Essa divisão ocorreu a partir do processo de profissionalização do futebol que se deu na capital federal, consolidado nesse mesmo ano. ${ }^{7}$

Alguns fatores relacionados ao êxodo de jogadores que passou a ocorrer no Brasil a partir do final da década de 1920,8 influenciaram no enfraquecimento do amadorismo no futebol do Rio de Janeiro e de outras localidades do país. Além disso, já era muito comum os atletas receberem remunerações nesse período, denominadas de "bichos". Esse cenário configurou o "amadorismo marrom", ou seja, mesmo em um contexto ainda amador, já existiam formas de se lucrar e

\footnotetext{
${ }^{6}$ COUTINHO. Um Flamengo grande, um Brasil maior, p. 48.

7 Todavia, já na década de 1920, diversos são os debates acerca da profissionalização do futebol no Rio de Janeiro, notadamente a partir de $1923 \mathrm{com}$ o título carioca inédito do Clube de Regatas Vasco da Gama. Maiores informações ver MORAES. Jogadas Insólitas; MALAIA. Revolução Vascaína; e SOARES. Futebol, raça e nacionalidade no Brasil.

${ }^{8}$ DRUMOND, O esporte como política de Estado; MALAIA. Revolução Vascaína, p. 409-410.
} 
ganhar dinheiro pelo futebol. ${ }^{9}$ Tais valores eram distribuídos para muitos atletas como forma de premiações e pagamentos de acordo com as partidas, vitórias ou títulos alcançados.

Todavia, entendemos que o fator desencadeador da profissionalização, sem desvalorizar a importância desses outros motivos explicitados, foi uma disputa pelo poder do futebol carioca ocasionada entre dirigentes de clubes da cidade e que ficou denominada como "dissídio esportivo".

Como já demonstrado em outras oportunidades, ${ }^{10}$ até então, a entidade máxima do futebol nacional era comandada por um grupo ligado a Arnaldo Guinle, importante dirigente vinculado ao Fluminense e membro de uma das famílias mais ricas e influentes da capital, tal como do país. Antes da década de 1930, esse grupo possuía o poder político da CBD, entidade que Guinle presidiu entre 1916 e 1920.

Porém, a partir dos anos 1930, período em que o país passou a ser governado por Getúlio Vargas, novos nomes ascenderam como detentores do poder no futebol, tendo Guinle e seus aliados ficado em "segundo plano". Esse novo grupo possuía também importantes figuras da sociedade e da política nacional, como os dirigentes João Lyra Filho, Rivadavia Corrêa Meyer e Luiz Aranha, sendo esse último oriundo do Rio Grande do Sul (assim como Vargas) e irmão de Oswaldo Aranha, um dos integrantes principais do Clube 3 de Outubro. ${ }^{11}$

0 fato de ter sido irmão de Oswaldo Aranha, que era amigo pessoal de Getúlio Vargas e ministro de seu governo, explicita a relação próxima que Luiz Aranha possuía com o presidente do período retratado. ${ }^{12}$ Além disso, Luiz Aranha

\footnotetext{
${ }^{9}$ DRUMOND, O esporte como política de Estado, p. 218.

${ }^{10}$ GOMES, O olhar político para o futebol em seu período de profissionalização, p. 83. Utilizamos algumas informações desse referido artigo para assim melhor explicitar algumas das peculiaridades do processo de profissionalização do futebol no Rio de Janeiro, ao qual já problematizamos em outros trabalhos.

${ }^{11}$ O Clube 3 de Outubro foi criado em 1931 pelos integrantes do movimento tenentista que, no ano anterior, havia apoiado a revolução que resultou na deposição do então presidente Washington Luís e na entrada de Getúlio Vargas ao poder. Entre seus integrantes principais, se encontrava Oswaldo Aranha, irmão de Luiz Aranha, que na fundação do clube havia assumido o posto de terceiro vice-presidente. Maiores informações ver CRUZ. Clube 3 de Outubro.

${ }^{12}$ Como destaca DRUMOND. Estado novo e esporte, p. 75, Vargas se referia a Luiz Aranha como "Lulu" Aranha, demonstrando a intimidade existente entre ambos. Mais informações, ver VARGAS. Diário.
} 
se tornaria, inclusive, presidente da CBD entre os anos de 1936 e 1943, o que ilustra o poder que passou, junto de seu grupo, a obter na entidade.

Com isso, a profissionalização se consolidou como uma opção para que o antigo grupo detentor do poder no futebol nacional, liderado por Arnaldo Guinle, pudesse buscar novamente seu espaço político no esporte, rivalizando com o predomínio dos novos dirigentes na CBD. Guinle e seus aliados enxergavam na criação de uma entidade profissional a única opção de alcançarem novamente o domínio político do futebol carioca e nacional.

Foi nesse momento de disputas e tensões pelo poder do futebol que, em janeiro de 1933, ${ }^{13}$ foi fundada a LCF, a primeira entidade de futebol profissional da cidade do Rio de Janeiro. Tal iniciativa se deu a partir de um movimento liderado, além de Guinle, por dirigentes como Antônio Avellar e Ary Franco, ${ }^{14}$ ligados respectivamente aos clubes America e Bangu, que juntos do Vasco da Gama, foram as equipes fundadoras da instituição. Dos grandes clubes, apenas o Botafogo e o Flamengo ${ }^{15}$ haviam se oposto aos ideais da profissionalização, permanecendo ambos na liga amadora da AMEA. Porém, ainda em maio de 1933, o Flamengo também se filiou à liga profissional que emergia, ${ }^{16}$ assim como o São Cristóvão. ${ }^{17}$

Os reflexos da profissionalização do futebol no Rio de Janeiro ainda se expandiriam para outras localidades do país. ${ }^{18}$ Especificamente na capital federal, com o surgimento da LCF, que se tornou a mantenedora da competição profissional de futebol na cidade, a AMEA passou a não reinar mais sozinha no desenvolvimento desse esporte. Naturalmente, como as equipes se dividiram entre as duas competições, era mais que esperado que o público também fosse repartido,

\footnotetext{
${ }^{13}$ A Noite, 24 de janeiro de 1933, p. 8.

${ }^{14}$ A Noite, 24 de janeiro de 1933, p. 8.

${ }^{15}$ A Noite, 24 de janeiro de 1933, p. 8.

${ }^{16}$ A Noite, 13 de maio de 1833 , p. 8.

${ }^{17}$ NAPOLEÃO. História das Ligas e Federações do Rio de Janeiro (1905-1941), p. 103.

${ }^{18}$ Se juntaram a capital federal as federações de futebol dos estados de São Paulo, Minas Gerais, Paraná e o estado do Rio de Janeiro autônomo e separado do Distrito Federal. A Associação Paulista de Esportes Atléticos (APEA), que era a entidade de São Paulo filiada à CBD, se desvinculou da entidade nacional e também adotou o regime profissional. Depois, a Federação Fluminense de Football, que representava o estado do Rio de Janeiro, a Liga Mineira, representante de Minas Gerais, e a Federação Paranaense de Desporto, do estado do Paraná, seguiram o mesmo caminho, formando assim a Federação Brasileira de Football (FBF). Maiores informações, ver GOMES. O futebol vira profissão.
} 
tendo em vista aqueles que acompanhavam o Campeonato Carioca amador até então.

Porém, com essa nova configuração, ocorreu uma concentração das equipes de maior qualidade na nova liga profissional organizada pela LCF. Em seu campeonato, passaram a jogar os times do Fluminense, Bangu, America, Vasco, Bonsucesso e Flamengo. Já na AMEA, apenas o Botafogo permaneceu das grandes equipes, tendo enfrentado a partir de 1933 equipes de menor expressão como o Olaria, Portuguesa, Andarahy, Engenho de Dentro, Cocotá, Mavilis, SC Brasil, Confiança e River.

Para o Botafogo, permanecer na AMEA era importante, já que estava inserido no novo contexto de domínio político do esporte na cidade a partir da CBD, principalmente por sua ligação com as figuras de Rivadavia Corrêa Meyer,19 João Lyra Filho e Luiz Aranha. ${ }^{20}$

Nesse cenário, podemos perceber que o profissionalismo não só consolidou o retorno do grupo de dirigentes liderados por Arnaldo Guinle ao comando de uma liga de futebol, como também reformulou o público que assistia aos jogos do esporte no Rio de Janeiro. Como a LCF passava a ter os principais clubes da cidade, além de possuir a partir de então um campeonato profissional, pôde desenvolver também uma lógica do espetáculo em seu âmbito, aumentando a possibilidade de públicos de diferentes localidades e camadas sociais assistirem as partidas da competição que organizava. Tratava-se de um ideal comercial, inerente a formação de espetáculos das mais diversas naturezas, que se inseria no cotidiano esportivo carioca.

A partir de 1935, uma nova organização modificaria novamente o desenvolvimento do futebol espetacularizado no Rio de Janeiro. Como havia perdido parte de seu público, com a debandada de suas principais equipes para a competição profissional da LCF, a AMEA buscou nesse ano uma nova forma de se inserir nessa lógica profissional em que o esporte se enquadrava.

\footnotetext{
${ }^{19}$ SOUZA. O Brasil entra em campo!, p. 42-43.

${ }^{20}$ DRUMOND. Estado Novo e esporte, p. 75.
} 
Com a implantação do regime livre, ${ }^{21}$ por parte da CBD, o campeonato da AMEA pôde também se inserir na lógica do futebol enquanto espetáculo. Tal propósito contrariava a proposta amadora da instituição e ainda sofria resistência por parte das camadas mais elitistas ligadas a seus clubes filiados.

Porém, se incluir no novo cenário significava uma forma de sobrevivência na nova realidade do esporte no Rio de Janeiro, assim como no Brasil. Não só o futebol, mas outras práticas também desenvolviam seus processos de profissionalização nesse período. Com isso, se excluir desse cenário, que cada vez mais transformava o esporte em algo que pudesse ser comercializado, seria fechar as portas de sua prática para o âmbito interno de seus clubes.

Assim, em 1935 os clubes da AMEA se incluíram definitivamente e com maior força nesse processo de espetacularização do esporte a partir da profissionalização, tendo sido inclusive criada uma nova entidade, então nomeada como Federação Metropolitana de Desportos (FMD). Mesmo sem a priori deixar de lado a lógica amadora, com o regime livre implantado, a nova instituição passou a aceitar também equipes e jogadores assumidamente profissionais. Além disso, teve o retorno de outros times que outrora fizeram parte das competições da AMEA, como Vasco da Gama, São Cristóvão e Bangu.

Com o avanço do campeonato da FMD, a LCF teve paulatinamente seu torneio enfraquecido, passando agora a dividir o público conquistado nos espetáculos futebolísticos com a outra organização. Todavia, os clubes de seu âmbito adotaram uma forma de se incluir ao processo de políticas nacionalistas criadas por Vargas no período, notadamente o Flamengo. Como destaca Renato Soares Coutinho,

\begin{abstract}
A torcida do Flamengo se reuniu em torno do maior projeto de propaganda política já organizado no Brasil: o nacionalismo trabalhista. As paixões políticas imbricadas em meio ao linguajar futebolístico reforçam que o futebol por si só não faz ninguém torcer por um clube. São as visões sociais de mundo que orientam as escolhas dos torcedores. [... Localizei] o vocabulário da cultura política trabalhista como elemento central da identidade flamenga. Claro que isso não significa que todas as pessoas ligadas ao clube sejam vinculadas a um determinado partido político. Mas quer dizer que a instituição que foi imaginada nos 1930 tem uma trajetória bastante associada à formação do discurso nacionalista presente nas teses trabalhistas. A "nação rubro-negra" e a
\end{abstract}

\footnotetext{
${ }^{21}$ O regime livre foi uma medida adotada pela CBD a partir de 1935, onde passou a aceitar, em um mesmo campeonato, equipes amadoras e profissionais. Ver DRUMOND. O esporte como política de Estado, p. 223.
} 
"nação brasileira trabalhista" compartilharam e fidelizaram em grande parte os mesmos adeptos e por motivos muito semelhantes. ${ }^{22}$

Esse cenário se manteria configurado até 1937. Durante esse período, ocorreria a primeira grande intervenção estatal varguista relacionada ao esporte e, especialmente, ao futebol. Essa se deu no âmbito da Censura Teatral, ${ }^{23}$ que possibilitou ao governo regulamentar e registrar os atletas que praticavam futebol no país.

O fato é que somente em 1937 que ocorreria uma modificação definitiva no âmbito do futebol profissional carioca que enfraqueceria de vez o discurso amador, refletindo mais uma vez o cenário nacional. Nesse ano foi realizada uma proposta de pacificação pelos clubes cariocas América e Vasco da Gama, visando encerrar as tensões geradas até então pelo processo de profissionalização do futebol na cidade. ${ }^{24}$ Dessa proposta, nasceu um pacto assinado entre os dois clubes citados, que se estendeu às outras equipes da LCF e da FMD. Esse pacto foi, apesar de algumas tensões iniciais, aceito pelos outros clubes e resultou na criação de uma nova instituição mantenedora do futebol carioca.

A imprensa aflorou essas tensões, em um primeiro momento, tendo cada jornal buscado valorizar o pacto como sendo mais favorável para o seu lado. 0 Jornal do Brasil, defensor da CBD, publicou que os dirigentes da FBF haviam ficado revoltados com o acordo. ${ }^{25}$ Todavia, o Jornal dos Sports, que defendia a entidade profissional, publicou essa matéria, nas palavras do então vice-presidente da FBF, Plínio Leite:

O contentamento é geral pelo prenuncio da terminação do dissídio do football nacional. Como vice-presidente da Federação Brasileira de Foot-ball cabe-me afirmar que o gesto do America assignando o pacto com o Vasco nada mais é do que ser ele o representante verdadeiro da opinião de todos os seus companheiros de lutas e que com eles estão solidários como sempre estiveram. ${ }^{26}$

\footnotetext{
${ }^{22}$ COUTINHO. Um Flamengo grande, um Brasil maior, p. 141.

${ }^{23}$ A Censura Teatral era um órgão ligado à polícia do período do governo Vargas, que criou regras específicas para a realização de várias diversões públicas e populares desse contexto, dentre elas o teatro e as práticas esportivas. Maiores informações sobre a Censura Teatral, ver BRAGA. Estado novo.

${ }_{24}^{24}$ Jornal dos Sports, 20 de julho de 1937, p. 1 e 6.

25 Jornal do Brasil, 20 de julho de 1937, p. 16.

${ }^{26}$ Jornal dos Sports, 20 de julho de 1937, p. 1 e 6.
} 
Superadas as divergências, em 1937 foi criada uma nova liga de futebol profissional no Rio de Janeiro, a Liga de Futebol do Rio de Janeiro (LFRJ). A intenção foi a de criar uma nova entidade, de forma que fossem extintas a FMD e a LCF. Com isso, a LFRJ passou a ser filiada a FBF, enquanto essa última era ligada a CBD.

Nessa nova configuração, os dirigentes ligados ao Botafogo, que como demonstramos tinha alguns importantes nomes vinculados à CBD, entenderam que o clube teria que se inserir definitivamente na lógica profissional que se consolidava, oficializando assim o amadorismo marrom que já era praticado na instituição. Como demonstramos até aqui, mais que um efeito das disputas entre "profissionais x amadores", essa ação caracterizou novamente uma tentativa do clube se manter no poder do futebol no Rio de Janeiro, dentro do cenário que se desenhava.

A partir de então, iniciando-se por São Paulo, os outros estados brasileiros foram aderindo à nova realidade e se filiando com suas ligas à FBF. Nessa nova organização, a CBD passava a ter o poder "apenas" dos assuntos referentes à seleção brasileira, enquanto os campeonatos estaduais de clubes seriam de responsabilidade da FBF. Portanto, apesar da oficialização do profissionalismo ter sido inevitável e aceita pelos dois lados após diversas tensões, esse acordo fez também com que a centralização do futebol realizada pela entidade esportiva máxima do país diminuísse, ${ }^{27}$ fato que permaneceria pelo menos até a criação do Conselho Nacional de Desportos (CND) em 1941.

\section{POLÍTICA, FUTEBOL E IDENTIDADE NACIONAL: POSSÍVEIS OLHARES}

Com o acordo definido em 1937, que marcou a união dos campeonatos da LCF e da FMD, surgindo assim um único campeonato profissional que passou a ser ligado à $\mathrm{FBF}^{28}$, pôde-se definir uma lógica de difusão e implantação do espetáculo a partir do futebol, teoricamente com menos tensões e conflitos. Com isso, o futebol

\footnotetext{
27 Jornal dos Sports, 20 de julho de 1937, p. 1 e 6.

${ }^{28}$ Mais informações sobre o processo de formação da FBF, ver GOMES. O futebol vira profissão.
} 
carioca passou a ser difundido via imprensa escrita e radiofônica não só para o Rio de Janeiro, mas para todo o país. Isso explica, em partes, o porquê de alguns clubes da então capital possuírem torcidas espalhadas por várias regiões do país, alguns mais e outros menos. Porém, mais do que reproduzir a versão já quase "mitológica" do rádio enquanto criador do futebol de massas carioca e nacional, entendemos que alguns outros fatores também foram importantes nessa configuração, notadamente no que se diz respeito ao ideário nacionalista do Estado Novo varguista.

Coutinho destaca que,

\begin{abstract}
A ideia difundida pelo jornalismo esportivo brasileiro que atribui à Rádio Nacional papel de protagonismo no processo de nacionalização do Flamengo precisa ser relativizada. A Rádio Nacional transmitia os jogos do futebol carioca. É claro que isso foi fundamental para os clubes do Rio de Janeiro. Mas o mesmo processo de nacionalização e popularização não pode ser verificado no Botafogo e no Fluminense. É verdade que esses dois clubes possuem adeptos em todo o Brasil, mas em uma escala bastante inferior. Dessa forma podemos dizer que o rádio foi de fato importante para a divulgação do Flamengo, como foi para os outros clubes fluminenses. Mas a ampla popularização do clube só foi possível por conta da marca associada ao Flamengo, que, ao contrário dos outros três grandes cariocas, se vinculou ao nacionalismo. ${ }^{29}$
\end{abstract}

Esse cenário nacionalista escancarava o profissionalismo no futebol carioca e nacional. Mesmo assim, a CBD não saiu muito satisfeita após a proposta de pacificação realizada pelos clubes cariocas America e Vasco da Gama ser efetivada, ${ }^{30}$ tendo em vista que o controle dos clubes por parte da FBF passou a ser mais concreto, como demonstramos.

Porém, mesmo com essa "derrota momentânea" da CBD, 1937 também ficou marcado como o ano em que as políticas estatais se concretizariam de forma mais direta com os esportes e o futebol. Nesse ano, houve um maior desenvolvimento da Educação Física enquanto política de Estado. Tendo como exemplo os governos nazifascistas do período, Vargas e seus aliados entendiam que o desenvolvimento da "mocidade brasileira" a partir de uma ótica militar e de desenvolvimento do corpo, seria o melhor caminho para o avanço da juventude e da nação. Drumond nos demonstra que,

\footnotetext{
${ }^{29}$ COUTINHO. Um Flamengo grande, um Brasil maior, p. 48.

${ }^{30}$ Jornal dos Sports, 20 de julho de 1937, p. 1 e 6.
} 
Já na Constituição de 1937, Francisco Campos deixou aberto o espaço para a criação de uma organização da juventude nacional, estabelecendo que a infância e a juventude deveriam receber cuidados especiais do Estado (art. 127). [...] Ao destacar como função de tais instituições a promoção da "disciplina moral" e do "adestramento físico" dos jovens, estabelecia-se a oportunidade de criação de uma organização nacional como a da Juventude Hitlerista, dos Balillas italianos ou mesmo como a Mocidade Portuguesa. [...] No entanto, o anteprojeto de Francisco Campos nunca saiu do papel. [...] Já Gustavo Capanema reformula o projeto por completo e eventualmente cria outro projeto para uma entidade da juventude nacional. Inspirado pelo que chama de "nome singelo" da organização congénere portuguesa, o ministro propõe o nome Juventude Brasileira (JB), o que marcaria o vínculo da organização com o país. [...] Por fim, a Juventude Brasileira é criada em março de 1940, através da promulgação do Decreto-Lei n. 2.072, apresentando como finalidade "promover, dentro ou fora das escolas, a educação cívica, moral e física da juventude, assim como da infância em idade escolar". ${ }^{31}$

Ao analisarmos mais especificamente essa relação do Estado com o futebol e sua profissionalização, o ano de 1937 também se torna chave para entendermos o posicionamento do governo. Desde 1935, a partir de uma adaptação realizada na "Lei Getúlio Vargas",32 a já citada Censura Teatral influenciava diretamente no controle de contratos de jogadores de futebol, assim como na difusão de padrões para o comportamento desses atletas, sendo tudo isso monitorado pela polícia do período. Esse enquadramento era o mesmo que já acontecia no meio artístico de então, como no caso do teatro. A partir de 1937, com a regulamentação definitiva da profissionalização desse esporte, esse controle se tornou ainda maior, tendo em vista que foi também nesse ano que se iniciou o Estado Novo.

0 auge das intervenções políticas varguistas com o futebol ocorreria na Copa do Mundo de 1938, realizada na França. A partir desse evento, o futebol passou a ter um uso político mais forte por parte do Estado, se transformando em uma importante forma de se construir e idealizar a identidade nacional brasileira. Denaldo de Souza demonstra que

Os governantes prestavam apoio à delegação brasileira. 0 presidente Getúlio Vargas concedeu duzentos contos. Já o interventor federal no Rio Grande do Sul ofereceu mais dez contos. Alzira Vargas, por sua vez, foi escolhida para ser a madrinha da seleção. Ela aceitou prontamente. Antes da viagem para a França, Getúlio fez questão de receber os atletas. Recomendou que voltassem como campeões mundiais, pois o título seria de suma importância para o futuro do país. 0 presidente chegou a dar uma declaração prometendo "casa própria para

\footnotetext{
${ }^{31}$ DRUMOND. Estado Novo e esporte, p. 132-134.

${ }^{32}$ Decreto-Lei 5.492, de 16 de julho de 1928.
} 
os craques, o prêmio oferecido pelo chefe da nação se o Brasil levantar o campeonato mundial". 33

Assim como outras práticas culturais, dentre elas o samba e a capoeira, o futebol em 1938 se enquadrou no discurso do Brasil enquanto um país da "democracia racial". Esse discurso, que buscava construir a identidade brasileira como a nação do encontro das "três raças" (brancos europeus, negros africanos e indígenas americanos), seria muito difundido nas décadas posteriores a partir de trabalhos realizados por importantes acadêmicos do país, como o sociólogo Gilberto Freyre, ${ }^{34}$ assim como pelas releituras feitas sobre as obras desse e outros pesquisadores.

Todavia, já na década de 1930, esse debate aparecia com força também no âmbito do futebol, inclusive por escritos do próprio Gilberto Freyre ${ }^{35}$ e do jornalista Mário Rodrigues Filho, ${ }^{36}$ com quem o sociólogo mantinha certa proximidade. ${ }^{37}$ Com a obra desses e outros autores, começou-se a construir a ideia de que os atletas negros do futebol brasileiro possuíam uma "malevolência" e um diferente gingado que contrastavam com o "frio" futebol europeu, demarcando assim o encontro das diferentes "raças" que em nosso país habitavam. Como escreve Freyre, em relação à boa participação brasileira na Copa de 1938,

[...] uma das condições dos nossos triunfos, este ano, me parecia a coragem, que afinal tivemos completa, de mandar a Europa um team fortemente afrobrasileiro. Brancos, alguns, é certo; mas grande número, pretalhões bem brasileiros e mulatos ainda mais brasileiros. [...] 0 novo estilo de jogar foot-ball me parece contrastar com o dos europeus por um conjunto de qualidades de surpresa, de manha, de astúcia, de ligeireza e ao mesmo tempo de espontaneidade individual em que se exprime o mesmo mulatismo de que Nilo Peçanha foi até hoje a melhor afirmação na arte política. [...] Acaba de se definir de maneira inconfundível um estilo brasileiro de foot-ball; e esse estilo é mais uma expressão do nosso mulatismo ágil em assimilar, dominar, amolecer em dança, em curvas ou em músicas técnicas europeias ou norte-americanas mais

\footnotetext{
${ }^{33}$ SOUZA. O Brasil entra em campo!, p. 63.

${ }^{34}$ Ver FREYRE. Casa-grande e senzala. Apesar de, nesse livro, Freyre não utilizar o termo "democracia racial", o mesmo é usado pelo autor posteriormente em outros trabalhos, tendo como base algumas das hipóteses levantadas nessa obra clássica citada.

${ }^{35}$ Ver FREYRE. "Foot-ball mulato".

${ }^{36}$ Ver RODRIGUES FILHO. O negro no futebol brasileiro.

${ }^{37}$ Mário Rodrigues Filho reproduzia, em suas análises sobre o futebol carioca e brasileiro, muitas das teorias propostas por Gilberto Freyre, acerca da tese da miscigenação presente no país. Freyre, inclusive, escreveu o prefácio da primeira edição do livro clássico de Rodrigues Filho lançado em 1947, O negro no futebol brasileiro, tendo essa obra sido fruto das reflexões que o jornalista produziu a partir da década de 1930, principalmente em sua atuação no Jornal dos Sports, periódico que se tornou proprietário a partir de 1936.
} 
angulosas para o nosso gosto. [...] 0 mulato brasileiro deseuropeisou o foot-ball dando-lhe curvas. [...] 0 estilo mulato, afro-brasileiro, de foot-ball é uma forma de dança dionisíaca. ${ }^{8}$

Com isso, parte desse discurso foi adotado pela política do período. E a Copa do Mundo de 1938 foi o auge dessa utilização política do futebol até então. Nunca antes uma competição esportiva mundial havia alcançado tanto destaque no país. Mais do que um simples discurso, a Copa de 1938 marcou simbolicamente o fim das disputas entre as federações, que fizeram com que o Brasil fosse com equipes inferiores nos dois mundiais ocorridos anteriormente. ${ }^{39}$ Além disso, a equipe alcançou seu melhor resultado até então em Copas do Mundo, ficando na terceira colocação e mostrando ao mundo o talento de jogadores negros, como Leônidas da Silva e Domingos da Guia, fundamentais na construção identitária do país enquanto uma "nação miscigenada".

Dessa forma, entender o futebol como um caminho para pensar a nação se tornava uma das chaves do país nesse momento, tendo o governo varguista não ignorado esse processo. Os discursos acerca da nacionalidade brasileira, fundamentais na construção de uma identidade nacional, se consolidavam no país a partir do futebol. Nesse sentido, a atuação de intelectuais, como Freyre, contribuiu significativamente para esse processo.

Sendo assim, podemos destacar que o processo de espetacularização do esporte, assim como sua popularização, esteve inserido dentro de uma lógica maior de um projeto nacionalista que permeava o âmbito político do país e que foi adotado pelas lideranças do futebol. A Copa do Mundo de 1938 foi um momento chave para tal construção, pois sendo o país da "democracia racial" no futebol, se consolidou uma ideia a ser vendida para o público. Assim, fazer com que essa

\footnotetext{
${ }^{38}$ Diário de Pernambuco, 18 de junho de 1938.

${ }^{39}$ Em 1930 o Brasil não conseguiu levar seus melhores jogadores para o mundial devido uma disputa entre as principais federações estaduais de futebol do período, que eram as da capital Rio de Janeiro e de São Paulo. Não tendo nenhum membro na delegação, a federação paulista não liberou seus atletas para disputarem a competição. Enquanto isso, em 1934 a divisão ocorreu devido as disputas entre as federações defensoras do profissionalismo e do amadorismo, onde a CBD (entidade que defendia o amadorismo) chegou a ter que contratar atletas profissionais, devido esses não terem sido liberados pela FBF (entidade profissional). Mais informações sobre o caso de 1934, ver GOMES. O futebol vira profissão e O Brasil na Copa do Mundo de 1934.
} 
marca fosse difundida em espetáculos, foi um dos caminhos seguidos pelos clubes de então.

Do Rio de Janeiro, o clube que mais entendeu e se adaptou a esse contexto foi o Clube de Regatas do Flamengo. Não à toa, a espetacularização do esporte andou junto com seu processo de popularização plena. Tendo adotado uma lógica de divulgação da imagem muito similar ao modelo nacionalista então definido, o Flamengo foi o principal difusor desse processo entre os clubes, sendo uma engrenagem em um cenário maior que consolidou o futebol como sinônimo de identidade no Rio de Janeiro e no Brasil.

\section{ESPETACULARIZAÇÃO DO FUTEBOL NOS CLUBES CARIOCAS: DIFERENTES ABSORÇõES}

Um dos principais efeitos da profissionalização do futebol, ao analisarmos os casos de diversos países em que ocorreu esse processo, é o de proporcionar, de forma mais plena, o avanço da popularização dessa prática na sociedade em que está inserida. Sendo esse efeito maior em alguns casos e menor em outros, em relação ao Rio de Janeiro não foi diferente. Com o avanço do profissionalismo do futebol, gradativamente ocorreu uma maior abertura ao esporte não só para os atletas que o praticavam, mas também ao público que o assistia.

Esse caminho se deu a partir da lógica do espetáculo, em que o futebol se inseriu a partir do profissionalismo, como demonstramos na parte anterior do artigo. Naturalmente, ao transformar o esporte em uma forma de atração para a população, se consolidou o interesse em popularizar a prática, de forma que essa alcançasse um número cada vez maior de adeptos.

No caso carioca, a popularização explicitou a relação existente entre os processos de profissionalização e espetacularização do futebol, mesmo tendo esse último sido iniciado anteriormente, como abordamos. A partir da formação da LCF, em 1933, se construiu diversas maneiras de difundir a prática do futebol. Nesse sentido, também foram construídas identidades para cada clube que se inseria na lógica profissional então vigente, tendo maior destaque para os clubes considerados grandes da cidade. 
O Vasco da Gama idealizou uma representação identitária lusitana, muito marcada pela própria história do clube e pelos laços que possuía com Portugal. 0 Fluminense manteve uma lógica de construção identitária elitista, enquanto o Flamengo, a partir do mandato de José Bastos Padilha (1933-1936) adotou um discurso muito similar ao do governo varguista no período, relacionando o clube aos ideais de nacionalização. ${ }^{40}$

Nesse processo, o Botafogo, outro grande da cidade e que não estava inserido na competição profissional da LCF, acabou ficando de fora inicialmente. Como ainda se mantinha ligado a lógica amadora do esporte, mesmo que mais de forma simbólica e retórica do que prática, tendo em vista o "amadorismo marrom" que se fazia presente no clube desde a década anterior, a equipe acabou em um primeiro momento não se inserindo em um projeto específico de difusão da imagem clubista, como ocorreu na difusão espetacularizada do esporte profissional nos outros clubes citados. Assim, tal como o Fluminense, mas ainda negando a lógica profissional do esporte, manteve-se ligado às elites que cercavam o clube.

Um exemplo claro de como os interesses do Botafogo se diferenciavam nesse contexto dos seus rivais, é o caso de Leônidas da Silva. Após a Copa do Mundo de 1934, vários jogadores que haviam sido contratados pela $\operatorname{CBD}^{41}$ se tornaram atletas do clube alvinegro. 0 "diamante negro", como ficaria depois conhecido Leônidas, estava entre eles. Apesar de ainda não ter alcançado o estrelato posterior ao mundial de 1938, o jogador já era, em 1934, um dos grandes nomes do futebol brasileiro. Mesmo assim, e apesar de ter conquistado o título carioca de 1935 em seu primeiro ano de clube, o atleta não teve vida longa em General Severiano.

De acordo com Renato Soares Coutinho, a não permanência de Leônidas no Botafogo não se deu somente pelo fato do atleta ser negro:

[...] A questão central era ele não ser a tal "prata da casa", ou seja, o jogador formado no clube, o sócio. 0 jogador "prata da casa" tinha status, pois vinha de boa família e tinha bons empregos. Leônidas, negro, não possuía esses atributos. Por isso foi "dado" pelo Botafogo ao Flamengo, que fez de tudo para contratá-lo. O Flamengo, ao contratar Leônidas, não estava necessariamente

\footnotetext{
${ }^{40}$ Ver COUTINHO. Um Flamengo grande, um Brasil maior.

${ }^{41}$ Para a Copa do Mundo de 1934, como a FBF se negou a ceder os atletas de seus campeonatos para o selecionado nacional devido as disputas que possuía com a CBD, essa última optou por contratar alguns dos atletas inseridos nos clubes já profissionais. Maiores informações, ver GOMES. O Brasil na Copa do Mundo de 1934.
} 
levantando a bandeira contra o racismo, mas agindo de maneira profissional. Profissionalismo que não era o espaço da democracia racial em termos simbólicos, mas o espaço da ascensão material. ${ }^{42}$

Compartilhamos do posicionamento de Renato Soares Coutinho em relação ao olhar nacionalista que adotou a instituição Flamengo ao buscar contratar jogadores negros nos anos 1930. Todavia, não reiteramos que o discurso da "democracia racial", mesmo que de forma simbólica e imaginária, não estivesse presente nesses caminhos percorridos pelo clube carioca, como destaca o autor, a partir de uma interpretação do próprio sobre a obra de Mário Rodrigues Filho. ${ }^{43}$

Entretanto, a saída de Leônidas da Silva do Botafogo para o Flamengo, é um exemplo claro da posição que o Botafogo ocupava no seio do amadorismo. Esse posicionamento que, a priori mantinha o clube como último baluarte do regime e líder na $\mathrm{CBD}$, como assim acreditavam seus dirigentes, o diferenciou inicialmente da lógica profissional adotada pelos seus rivais, tendo em vista que a equipe foi a última entre as grandes da cidade a se inserir na lógica espetacularizada de mercado que o futebol havia alcançado.

Com a saída de Leônidas da Silva do Botafogo, o clube que melhor entendeu o momento pelo qual passava o país e seu futebol, foi o Flamengo. Dentro da lógica construída e já explicitada neste trabalho, de que o futebol poderia ser um dos caminhos para demonstrar a "democracia racial brasileira", sendo a posição dos negros importante nesse processo, o clube passou a fazer investimentos nesse sentido. Assim, se difundia a hipótese proposta por Mário Rodrigues Filho e Gilberto Freyre acerca da temática.

O futebol carioca passou a adotar uma lógica relacionada com o popular a partir desse recorte da profissionalização. 0 caso do Flamengo é o mais explícito nesse processo. Todavia, mesmo sendo apenas para grupos mais restritos, os outros clubes passaram a construir também um público, popularizando suas imagens e permitindo que o acesso ao esporte fosse possível para diversos interessados, sejam na condição de plateia ou de atleta.

Esse processo é um reflexo das políticas de inclusão e desenvolvimento trabalhista presentes no governo Vargas, notadamente no período do Estado Novo

\footnotetext{
${ }^{42}$ COUTINHO. Um Flamengo grande, um Brasil maior, p. 134.

${ }^{43}$ RODRIGUES FILHO. O negro no futebol brasileiro.
} 
(1937-45). A partir da lógica trabalhista, como destaca Ângela de Castro Gomes, ${ }^{44}$ não é nenhum absurdo pensar que o esporte, especialmente o futebol, tendo em vista sua já alcançada difusão, pudesse se apropriar de alguns sentidos. As políticas relacionadas à Educação Física e ao lazer,45 são demonstrações claras dos interesses políticos em popularizar as práticas corporais institucionalizadas nesse contexto.

Um outro bom exemplo é o da formação do Serviço de Recreação Operária, criado no período final do Estado Novo (1943-45). Como nos demonstra Angela Brêtas,

Este órgão, criado em 1943 pelo Ministério do Trabalho, Indústria e Comércio (MTIC), durante a gestão de Alexandre Marcondes Filho, teve Arnaldo Lopes Sussekind como seu primeiro presidente e estava destinado a organizar o lazer dos trabalhadores e de suas famílias com a finalidade de "coordenar os meios de recreação da classe operária, prestando aos sindicatos assistência e colaboração". 46

Tendo esse cenário como pano de fundo, popularizar práticas esportivas, como o futebol na era Vargas, não se tornou nenhum absurdo. Seja com ações diretas ou indiretamente ligadas ao governo, o futebol foi utilizado em várias localidades da "nação" como forma de se difundir uma construção identitária brasileira. No caso do Rio de Janeiro, como destacamos, o Flamengo foi o clube que mais abraçou essa ideia, consolidada durante o mandato do presidente José Padilha (1933-36).

\section{CONSIDERAÇõES FinAIS}

As imagens construídas nos clubes ainda seriam redefinidas no decorrer de suas histórias, por vários motivos. Entretanto, concluímos que em nenhum período anterior teria sido possível se construir um cenário de popularização do futebol como se deu nos anos 1930 e 40. Não só pela profissionalização do esporte, que estimulou a maior espetacularização do mesmo como já demonstramos, mas

\footnotetext{
${ }_{44}^{44}$ GOMES. A invenção do trabalhismo.

${ }^{45}$ MELO. Escola Nacional de Educação Física e Desportos.

${ }^{46}$ BRÊTAS. Nem só de pão vive o homem.
} 
também pela configuração política de então, relacionada ao trabalhismo varguista e a inserção de camadas populares nos diferentes setores sociais.

Esse processo abriu espaço, inclusive, para o desenvolvimento de um campo autônomo de outras práticas culturais nesse período, como os já citados, samba ${ }^{47} \mathrm{e}$ capoeira. Antes consideradas por muitos como inadequadas, práticas de "malandros" ou "marginais", ambas também foram entendidas nesse processo de construção da identidade nacional, como parte da difusão da teoria freyriana do "Brasil miscigenado" (ou, pelo menos, da difusão das interpretações, equivocadas ou não, feitas sobre as teorias de Gilberto Freyre).

Em 1941, com a criação do CND e a consolidação de uma política centralizadora dos esportes, naturalmente passou a ocorrer um maior controle dos espetáculos produzidos por parte das entidades responsáveis. Nesse caso, estamos falando da CBD, tendo em vista a extinção da FBF no processo que foi iniciado com o surgimento do CND. Com isso, a CBD pôde estimular à sua maneira as formas de se vender o esporte, mantendo a partir de então uma relação mais próxima com as políticas nacionalistas inerentes ao governo Vargas. Todavia, a construção idealizada por Gilberto Freyre e Mário Rodrigues Filho, que valorizava a formação do povo brasileiro a partir do "encontro das três raças", sendo a posição do negro e de sua cultura fundamentais para definir a singularidade do país no futebol, já havia sido consolidada, seja no âmbito dos selecionados nacionais ou de clubes, como o Flamengo.

\section{Referências:}

BOURDIEU, Pierre. Como se pode ser desportista? In: Questões de sociologia. Lisboa: Fim do século, 2003, p. 181-204.

BRAGA, Suely. Estado Novo. In: Fundação Getúlio Vargas; Centro de Pesquisa e Documentação de História Contemporânea do Brasil. Fatos e imagens: artigos ilustrados de fatos e conjunturas do Brasil. Disponível em: https.goo.gl//9TQLQ. Acesso em 22 mar. 2016.

BRÊTAS, Angela. Nem só de pão vive o homem: criação e funcionamento do Serviço de Recreação Operária (1943-1945). Rio de Janeiro: Apicuri, 2010.

\footnotetext{
${ }^{47}$ Maiores informações sobre o caso do samba nesse período, ver VIANNA. O mistério do samba.
} 
CLARK, T. J. A pintura da vida moderna. São Paulo: Companhia das Letras, 2004.

COUTINHO, Renato Soares. Um Flamengo grande, um Brasil maior: o Clube de Regatas do Flamengo e a construção do imaginário político nacionalista popular (1933-1955). Rio de Janeiro: 7 Letras, 2014.

CRUZ, Adelina Novaes e. Clube 3 de Outubro. In: Fundação Getúlio Vargas; Centro de Pesquisa e Documentação de História Contemporânea do Brasil. Fatos e imagens: artigos ilustrados de fatos e conjunturas do Brasil. Disponível em goo.gl/JVa2mz. Acesso em 22 mar. 2016.

DRUMOND, Maurício. O "dissídio esportivo" e o processo de profissionalização do futebol no Rio de Janeiro (1933-1937). In: GOMES, Eduardo de Souza; PINHEIRO, Caio Lucas Morais (Org.). Olhares para a profissionalização do futebol: análises plurais. Rio de Janeiro: Multifoco, 2015, p. 73-91.

DRUMOND, Maurício. Estado Novo e esporte: a política e o esporte em Getúlio Vargas e Oliveira Salazar (1930-1945). Rio de Janeiro: 7 Letras, 2014.

DRUMOND, Maurício. O esporte como política de Estado: Vargas. In: DEL PRIORE, Mary; MELO, Victor (orgs.). História do esporte no Brasil: do império aos dias atuais. São Paulo: Ed. UNESP, 2009, p. 213-244.

FREYRE, Gilberto. [1947]. Prefácio. In: RODRIGUES FILHO, Mário. O negro no futebol brasileiro. Rio de Janeiro: Mauad, 2003.

FREYRE, Gilberto. Foot-ball mulato. Diário de Pernambuco, Recife, 18 jun. 1938.

GOMES, Ângela Maria de Castro. A invenção do trabalhismo. Rio de Janeiro: Vértice, 1988.

GOMES, Eduardo de Souza. O olhar político para o futebol em seu período de profissionalização. PODIUM: Sport, Leisure and Tourism Review, São Paulo, v. 5, n. 1, jan.-abr. 2016, p. 78-93.

GOMES, Eduardo de Souza. O futebol vira profissão: tensões e efeitos da profissionalização do futebol no Rio de Janeiro (1933-1941) e na Colômbia (19481954). 2016. 147 f. Dissertação (Mestrado em História Comparada) - Instituto de História, Universidade Federal do Rio de Janeiro, Rio de Janeiro, 2016.

GOMES, Eduardo de Souza. O Brasil na Copa do Mundo de futebol de 1934: tensões entre amadorismo e profissionalismo e os efeitos do fracasso do scratch nacional. Revista Contemporânea, Niterói, v. 2, n. 4, 2014, p. 1-29.

GOMES, Eduardo de Souza; PINHEIRO, Caio Lucas Morais (org.). Olhares para a profissionalização do futebol: análises plurais. Rio de Janeiro: Multifoco, 2015.

MALAIA, João. Revolução Vascaína: a profissionalização do futebol e a inserção sócio-econômica de negros e portugueses na cidade do Rio de Janeiro (1915-1934). 2010. 501 f. Tese (Doutorado em História Econômica) Faculdade de Filosofia, Letras e Ciências Humanas, Universidade de São Paulo, São Paulo, 2010.

MASCARENHAS, Gilmar. Entradas e bandeiras: a conquista do Brasil pelo futebol. Rio de Janeiro: EdUERJ, 2014. 
MELO, Victor Andrade de. Escola Nacional de Educação Física e Desportos: uma possível história. 1996. 207 f. Dissertação (Mestrado em Educação Física) - Faculdade de Educação Física, Universidade Estadual de Campinas, Campinas, SP, 1996.

MORAES, Hugo da Silva. Jogadas Insólitas: amadorismo e processo de profissionalização do futebol carioca (1922-1924). Rio de Janeiro: Multifoco, 2014.

NAPOLEÃO, Antônio Carlos. História das Ligas e Federações do Rio de Janeiro (1905-1941). In: SILVA, Francisco Carlos Teixeira da; SANTOS, Ricardo Pinto dos (org.). Memória social dos esportes: futebol e política: a construção de uma identidade nacional. Rio de Janeiro: Mauad, 2006, p. 81-105.

PEREIRA, Leonardo Affonso de Miranda. Footballmania: uma história social do futebol no Rio de Janeiro, 1902-1938. Rio de Janeiro: Nova Fronteira, 2000.

RODRIGUES FILHO, Mário. O negro no futebol brasileiro. 4⿳a edição. Rio de Janeiro: Mauad, 2003 [1947].

SANTOS JÚNIOR, Nei Jorge dos. A construção do sentimento local: o futebol nos arrabaldes de Bangu e Andaraí (1914-1923). Rio de Janeiro: Multifoco, 2014.

SOARES, Antônio Jorge. Futebol, raça e nacionalidade no Brasil: releitura da história oficial. 1998. 336 f. Tese (Doutorado em Educação Física) Universidade Gama Filho, Rio de Janeiro, 1998.

SOUZA, Denaldo Alchorne de. O Brasil entra em campo!: construções e reconstruções da identidade nacional (1930-1947). São Paulo: Annablume, 2008.

VARGAS, Getúlio. Diário. 2 vols. São Paulo: Siciliano; Rio de Janeiro: FGV, 1995.

VIANNA, Hermano. O mistério do samba. Rio de Janeiro: Zahar, 2008. 